\title{
ERPS TO WORDS - EFFECT OF GENDER AND SITE OF RECORDING ELECTRODE
}

\author{
Josef Petřek \\ Institute of Physiology, Faculty of Medicine, Palacký University, 77515 Olomouc, Czech Republic \\ e-mail:fesoj@tunw.upol.cz
}

Received: July 10, 2004; Accepted: September 4, 2004

Key words: ERPS/Words/Gender/Site of recording electrode

Event-related potentials (ERPs) to word stimuli were registered in 20 twenty-one-year-old students ( 7 males and 13 females) of the Faculty of Medicine of Palacký University. In an ideal case in the first $800 \mathrm{~ms}$ after the onset of stimulus ERP consists of three clear positive and four negative waves. The amplitude of some waves of ERPs shows a high degree of inter-individual variability. It was also revealed that the latency and amplitude of some ERPs waves to word stimuli depends on the gender and on the site of the registration electrode on the scalp of the subject. Latencies of components LP2 and LN4 in all electrodes are shorter in females than in males, component LN2 behaves reversely - its latency is shorter in males. On the other hand, the amplitude of dependent variables BP2, BN2 and PV1 is in most electrodes higher in females than in males - except for the amplitude of components BP4 and BN1.

\section{INTRODUCTION}

The neural system, responsible for language comprehension, must quickly process and integrate a large amount of heterogeneous linguistic data. At the present time there is no appropriate and generally acceptable description of the architecture of this system. This means that no model of language processing is available that will allow us, without problems, to interpret the wide range of disorders of language functions in neurological patients with focal lesions and explain the no less inconsistent results of experiments dealing with various aspects of language processing both in healthy people and in patients.

An effort to contribute to the solution of this problem motivated intensive research. Many researchers using modern electrophysiological recording techniques and metabolic imaging techniques (PET and MRI) have sought answers to the question "where“ and "how" in the brain are processed open class words and closed class words, nouns and verbs, or perhaps what is the temporal co-ordination and laterality of semantic and syntactic processes in language processing.

In the literature, the generally accepted view is that open and closed classes of words during language operation are processed by different functional systems of the

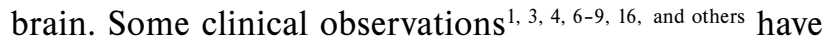
confirmed this.

Neuropsychological and neurobehavioral studies, however, say nothing about the way the open and closed classes of words are processed in the nervous system. More detailed information about this is provided by the recording and analysis of event-related potentials (ERPs). ERPs can be recorded from the scalp during cognitive activities of the brain. These are a sequence of positive and negative components about which it is assumed that each reflects the activity of a different functional system ${ }^{12}$.
The frequent contradictions in the findings, which a reader may quickly discover in literature, have stimulated us to design and carry out an experiment the outcome of which might contribute to the solution of some of these contradictory findings. In the course of an experiment we recorded ERPs to words at different sites of the participant's scalp. The off-line analysis of ERPs was expected to answer the following questions:

(1) Does the location of the recording electrode and the participant's gender affect the latency and amplitude of each ERPs waves to words?

(2) Are there differences in principal features of ERPs to nouns and ERPs to verbs? If so, does the location of the recording electrode and the gender have a share in it?

(3) Does the dynamic character of changes in ERPs to nouns or verbs reflect semantic differences of the stimuli that produced them?

Answers to these questions will be given in several presentations. This project is seeking an answer to the first question.

\section{METHODS}

\section{Subjects}

The subjects were 20 twenty-one-year students ( 7 males and 13 females) of the Faculty of Medicine of the Palacký University. All participants were right-handed. Their vision was normal or corrected to normal. The native language of all was Czech. All subjects gave their informed consent to the procedure.

\section{Stimuli}

The word stimuli ( 63 nouns, 63 verb and 21 animal names) were taken from an index of word frequency of Czech written language ${ }^{11}$. Additional 21 words were used 
in practice lists - none of these were used as experimental stimuli. The number of letters in a word ranged from five to eight (average number per word: noun 5.9, verb 6.6, animal names of 5.7).

Selected nouns and verbs were each subdivided according to Kellenbach's criteria into three semantic feature type subcategories that differed in the saliency of their visual-perceptual and motor components (see Appendix 1). Kellenbach et al. ${ }^{13}$ characterise subcategories of nouns and verbs as follows: "Abstract nouns and cognition verbs ('abstract' stimuli) are associated with no/few perceptual and no/few motor features; nonmanipulable objects and motion verbs ('visual' stimuli) are associated with clear visual/perceptual features, but no/few motor features; manipulable objects and action verbs ('motor'stimuli) are highly associated with both visual-perceptual and motor features".

The nouns and verbs of each subcategory were randomly classified into three blocks of 21 words each; animal names were also classified in three blocks - seven words per block. The balanced $7 \times 7$ Latin square design ${ }^{23}$ was used to arrange 49 words (21 nouns, 21 verbs and 7 animal names) in an experimental sequence. Three sequences were created for the whole experiment. During the experiment each sequence was used three times, making a total of nine blocks of stimuli whose sequence was randomised over subjects. All words were presented horizontally in capital letters. The timing of word stimuli was checked by a photodiode.

\section{Presentation of stimuli}

The Experimenter's WorkBench 32 Data Acquisition and Experiment Control Software (DataWave Technologies, Longmont, $\mathrm{CO}$ ) was used to control stimulus presentation, regulate the timing of events, and record the responses of participants. During the experiment participants were seated in a comfortable chair approximately $120 \mathrm{~cm}$ in front of a computer screen (SONY, Model: SDM-X72). They were tested individually in a darkened, sound-attenuated, and electrically shielded room. Stimuli appeared in white with grey background. When displayed, the stimuli subtended $0.43^{\circ}$ of vertical visual angle and $2.6^{\circ}-2.9^{\circ}$ of horizontal visual angle. A second monitor, located outside of the testing room, allowed the experimenter to view the stimulus presented on each trial.

Each sequence presentation began with central presentation of a white asterisk for one second. Within each sequence a word appeared on the screen for $250 \mathrm{~ms}$ with an inter-stimulus interval of $2750 \mathrm{~ms}$ separating words. Pauses of 1.5-2.0 minutes separated individual sequences.

Before the experiment began a practice set of 21 words was presented. The whole experiment lasted approximately one hour.

\section{Data acquisition}

EEG was recorded from 9 scalp sites by tin electrodes attached to an elastic cap (Electro-Cap International, Eaton, $\mathrm{OH}$ ). Electrodes were placed at scalp position $\mathrm{Cz}$, $\mathrm{F} 3, \mathrm{~F} 4, \mathrm{C} 3, \mathrm{C} 4, \mathrm{P} 3, \mathrm{P} 4, \mathrm{~T} 3$, and T4 of the international
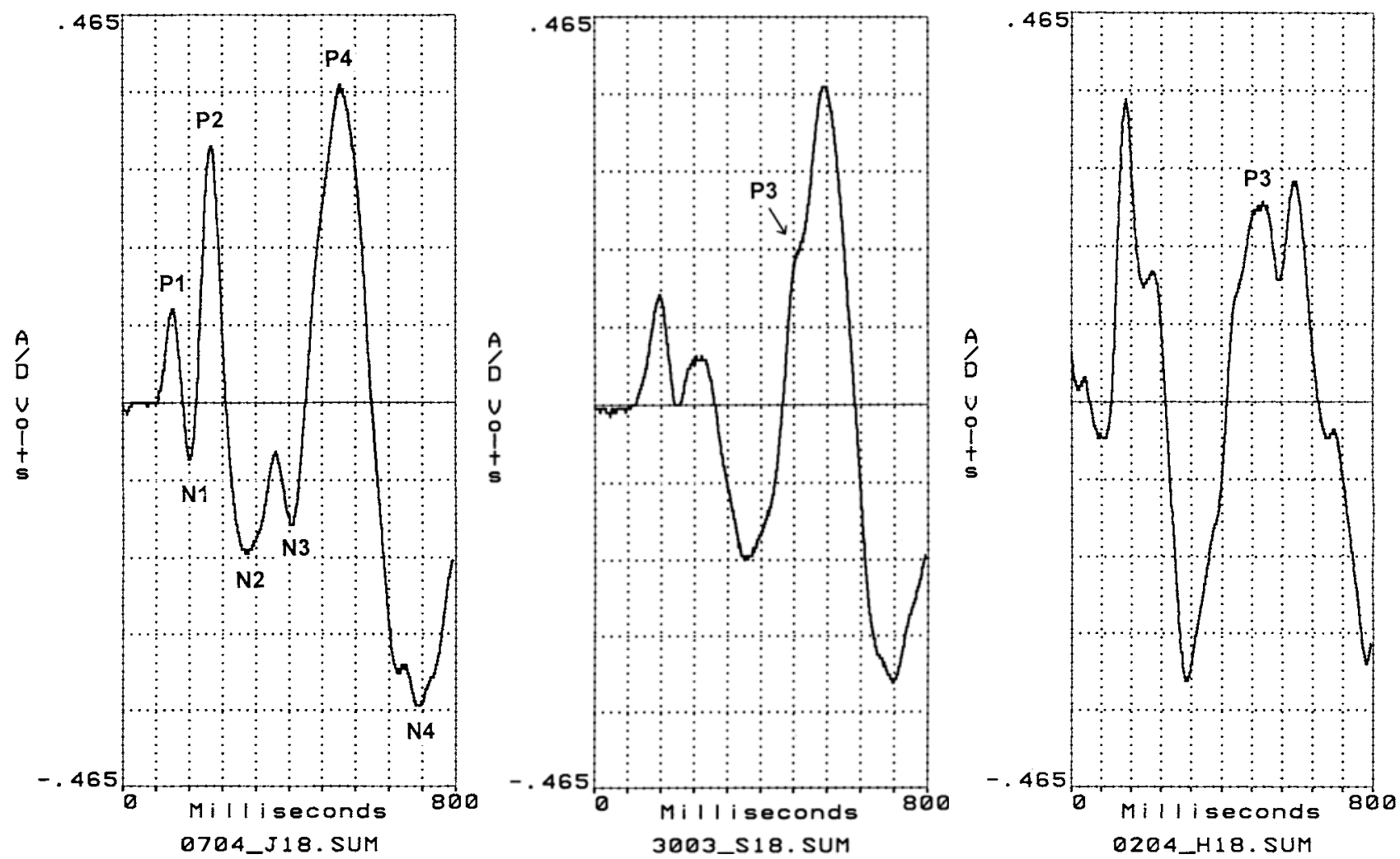

Fig. 1. Typical average ERPs to word at site $C 3$ in three subjects The positivity of individual waves of ERPs (upwards) is designated by symbol $\mathrm{P}$ the negativity (downwards) by $\mathrm{N}$. The moment of stimulation coincides with the onset of records. Amplitude calibration: $1 \mu \mathrm{V}=40 \mathrm{mV}$. 

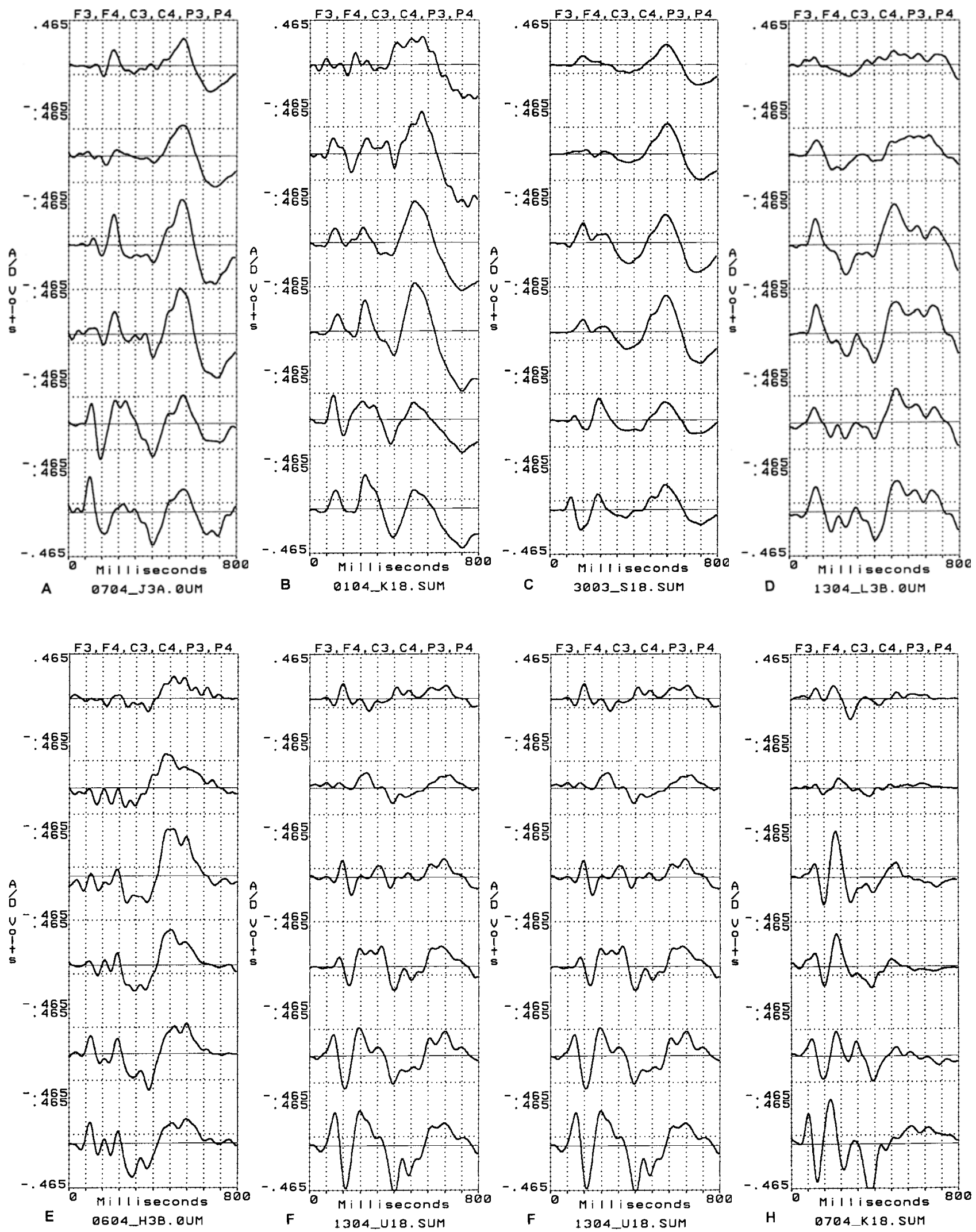

Fig. 2. Average ERPs to words recorded at six sites (F3, F4, C3, C4, P3, P4) in eight subjects (A, B, ..., H) For the others see the text to Fig. 1. 
10-20 system $^{10}$. One electrode was also placed at the outer canthus of the right eye to monitor eye movements. Scalp electrodes were referred to linked earlobes; the ground electrode was placed at Fpz. Electrodes impedance was kept below $3 \mathrm{k} \Omega$ throughout the experiment.

Following electrode application, subjects were instructed to read each word silently and attentively. They were also asked to focus on the asterisk whenever it appears on the screen and to avoid blinks or other movements during the presentation of stimuli.

The EEG signal was amplified by cascade of two amplifiers (amplifiers EKe, OTE Biomedica, Firenze, and Amplifier Neuralynx, Tucson, Arizona) with bandpass of $0.01-100 \mathrm{~Hz}$ and continuously sampled at $1 \mathrm{kHz}$ per channel by an A/D converter; the resolution of the system is $0.122 \mu \mathrm{V} /$ bit. The digitised records were saved to the hard disk of a computer for later off-line replay and analysis.

\section{Data analysis}

The DataWave CP Analysis Modules and Data Editing Software were used for off-line analysis of experimental data. The proper analysis ran as follows: Digital filtering of records (bandpass 1-30 Hz), cutting filtered records for averaging - the start points of the cut segment of EEG records are time-locked to photodiode signal, and detection of ERPs by averaging. Then the latencies and amplitudes of individual ERPs were measured; amplitudes were measured from baseline, which was calculated by software using the first five points of the waveform. Parameters of ERPs at sites T3 and T4 were not determined because they practically did not differ from ERPs parameters at frontal sites (F3/F4). StatSoft software package (StatSoft, Tulsa, OK) was used for statistic processing of the ERPs data.

\section{RESULTS}

\section{Features of ERPs to word stimuli}

A series of alternatively positive and negative waves characterise ERPs to word stimuli in participants of our experiment. In an ideal case (see Fig.1) in the first $800 \mathrm{~ms}$ after the onset of stimulus ERP consists of three distinct positive and four negative waves. The last positive wave, however, is usually not uniform and has high inter-individual variability. It is often comprised of two separate positive waves (see the record on the right side in Fig. 1 and records in Fig. 2E) or a plateau (Fig. 2D), which spans the trough between two positive peaks. In some individuals, one of the two positive waves can have a rather indistinct peak (the middle record in Fig. 1 and records in Fig. 2A). The distance between the peaks of the two positive waves is usually approximately $100 \mathrm{~ms}$, and that is the reason why we distinguish two separate positive waves - P3 and P4.

Very high inter-individual variability is also shown in waves N2 and N3 (compare records in Fig. 2). Basically, all that can be said about them was already said about waves $\mathrm{P} 3$ and $\mathrm{P} 4$. The remaining ERPs waves (P1, N1, P2 and N4) are fairly distinct in most individuals and only differ in the amplitude size (see records in Fig. 2).

Table 1. Multivariate analysis of variance: ERPs data

\begin{tabular}{|l|c|c|c|c|c|c|}
\hline & \multicolumn{6}{|c|}{ Table of all effects: ERPs data } \\
\hline Effect & Test & Value & F & Effect df & Error df & $\mathrm{p}$ \\
\hline Gender & Wilks & 0.605551 & 34.34 & 18 & 949.000 & 0.000000 \\
\hline Electrode & Wilks & 0.270033 & 12,94 & 108 & 5445.954 & 0.000000 \\
\hline Gender $\times$ Electrode & Wilks & 0.788947 & 2,13 & 108 & 5445.954 & 0.000000 \\
\hline
\end{tabular}

Table 2. Basic features of ERPs to words in males (1) and females (2)

\begin{tabular}{|c|c|c|c|c|c|c|c|c|c|c|c|c|c|c|c|c|c|c|c|}
\hline $\begin{array}{c}\text { Gen- } \\
\text { der }\end{array}$ & N & $\begin{array}{c}\text { L } \\
\text { LP1 }\end{array}$ & $\begin{array}{c}\text { A } \\
\text { BP1 }\end{array}$ & $\begin{array}{c}\text { L } \\
\text { LP2 }\end{array}$ & $\begin{array}{c}\text { A } \\
\text { BP2 }\end{array}$ & $\begin{array}{c}\text { L } \\
\text { LP }\end{array}$ & $\begin{array}{c}\text { A } \\
\text { BP3 }\end{array}$ & $\begin{array}{c}\text { L } \\
\text { LP4 }\end{array}$ & $\begin{array}{c}\text { A } \\
\text { BP4 }\end{array}$ & $\begin{array}{c}\text { L } \\
\text { LN1 }\end{array}$ & $\begin{array}{c}\text { A } \\
\text { BN1 }\end{array}$ & $\begin{array}{c}\text { L } \\
\text { LN2 }\end{array}$ & $\begin{array}{c}\text { A } \\
\text { BN2 }\end{array}$ & $\begin{array}{c}\text { L } \\
\text { LN3 }\end{array}$ & $\begin{array}{c}\text { A } \\
\text { BN3 }\end{array}$ & $\begin{array}{c}\text { L } \\
\text { LN4 }\end{array}$ & $\begin{array}{c}\text { A } \\
\text { BN4 }\end{array}$ & $\begin{array}{c}\text { A } \\
\text { PV1 }\end{array}$ & $\begin{array}{c}\text { A } \\
\text { PV2 }\end{array}$ \\
\hline 1 & 343 & 131.6 & 181.1 & $\mathbf{2 3 7 . 8}$ & $\mathbf{1 3 2 . 4}$ & 481.7 & $\mathbf{2 0 0 . 3}$ & 582.2 & $\mathbf{1 9 6 . 2}$ & $\mathbf{1 8 7 . 0}$ & $\mathbf{1 6 7 . 8}$ & $\mathbf{2 7 2 . 9}$ & $\mathbf{1 1 2 . 6}$ & 396.8 & 206.8 & $\mathbf{7 5 3 . 2}$ & $\mathbf{1 4 2 . 5}$ & $\mathbf{3 9 5 . 0}$ & $\mathbf{3 6 8 . 4}$ \\
2 & 637 & 132.8 & 190.3 & $\mathbf{2 2 4 . 5}$ & $\mathbf{2 3 9 . 0}$ & 485.0 & $\mathbf{1 7 6 . 4}$ & 583.7 & $\mathbf{1 3 0 . 3}$ & $\mathbf{1 7 5 . 2}$ & $\mathbf{1 1 3 . 0}$ & $\mathbf{2 9 2 . 7}$ & $\mathbf{1 4 8 . 5}$ & 400.1 & 215.5 & $\mathbf{7 1 5 . 4}$ & $\mathbf{1 8 4 . 5}$ & $\mathbf{4 8 8 . 6}$ & $\mathbf{4 1 0 . 0}$ \\
\hline
\end{tabular}

$\mathrm{N}$ - number of measurements in the set.

$\mathrm{L}$ - latencies (in ms) of positive (LP1, LP2, LP3, LP4) and negative (LN1, LN2, LN3, LN4) waves of ERPs.

A - amplitudes (in mV) of positive (BP1, BP2, BP3, BP4) and negative (BN1, BN2, BN3, BN4) waves of ERPs,

PV1 - voltage between peaks P1/P2 and valley N3, PV2 - voltage between peaks P3/P4 and valley N4; Amplitude calibration: $1 \mu \mathrm{V}=40 \mathrm{mV}$.

Bold numbers on a grey background - the difference between two means is significant at the $5 \%$ level. 
Table 3. Comparison of latencies and amplitudes of ERPs in different electrodes

\begin{tabular}{|c|c|c|c|c|c|c|c|c|c|c|c|c|c|c|c|c|c|c|c|}
\hline $\begin{array}{l}\text { Elec- } \\
\text { trode }\end{array}$ & $\mathrm{N}$ & \begin{tabular}{|c|}
$\mathrm{L}$ \\
$\mathrm{LP} 1$
\end{tabular} & $\begin{array}{c}\mathrm{A} \\
\mathrm{BP} 1\end{array}$ & \begin{tabular}{|c|}
$\mathrm{L}$ \\
$\mathrm{LP} 2$
\end{tabular} & $\begin{array}{c}\text { A } \\
\text { BP2 }\end{array}$ & \begin{tabular}{|c|}
$\mathrm{L}$ \\
$\mathrm{LP} 3$
\end{tabular} & $\begin{array}{c}\text { A } \\
\text { BP3 }\end{array}$ & \begin{tabular}{|c|} 
L \\
LP4
\end{tabular} & $\begin{array}{c}\text { A } \\
\text { BP4 }\end{array}$ & \begin{tabular}{|c|}
$\mathrm{L}$ \\
$\mathrm{LN} 1$
\end{tabular} & $\begin{array}{c}\text { A } \\
\text { BN1 }\end{array}$ & $\begin{array}{c}\mathrm{L} \\
\mathrm{LN} 2\end{array}$ & $\begin{array}{c}\text { A } \\
\text { BN2 }\end{array}$ & $\begin{array}{c}\mathrm{L} \\
\mathrm{LN} 3\end{array}$ & $\begin{array}{c}\mathrm{A} \\
\mathrm{BN} 3\end{array}$ & $\begin{array}{c}\mathrm{L} \\
\mathrm{LN} 4\end{array}$ & $\begin{array}{c}\text { A } \\
\text { BN4 }\end{array}$ & $\begin{array}{c}\text { A } \\
\text { PV1 }\end{array}$ & $\begin{array}{c}\text { A } \\
\text { PV2 }\end{array}$ \\
\hline $\mathrm{CZ}$ & 140 & 135.0 & 242.3 & 228.0 & 235.3 & 480.9 & 273.5 & 583.6 & 196.2 & 186.6 & 95.4 & 278.3 & 197.8 & 397.1 & 240.3 & 734.4 & 230.4 & 562.5 & 542.6 \\
\hline F3 & 140 & & $\downarrow$ & & $\downarrow$ & & $\downarrow$ & & $\downarrow$ & $\downarrow$ & & & $\downarrow$ & & $\downarrow$ & & $\downarrow$ & $\downarrow$ & $\downarrow$ \\
\hline $\mathrm{F} 4$ & 140 & $\uparrow$ & $\downarrow$ & $\uparrow$ & $\downarrow$ & & $\downarrow$ & & $\downarrow$ & & & & $\downarrow$ & & $\downarrow$ & & $\downarrow$ & $\downarrow$ & $\downarrow$ \\
\hline C3 & 140 & & $\downarrow$ & & $\downarrow$ & & $\downarrow$ & & & & & & $\downarrow$ & & & & & $\downarrow$ & $\downarrow$ \\
\hline C4 & 140 & & $\downarrow$ & & $\downarrow$ & & $\downarrow$ & & & & & & $\downarrow$ & & & & $\downarrow$ & $\downarrow$ & $\downarrow$ \\
\hline P3 & 140 & $\downarrow$ & $\downarrow$ & $\uparrow$ & & & $\downarrow$ & & $\downarrow$ & $\downarrow$ & $\uparrow$ & & $\downarrow$ & & $\uparrow$ & & $\downarrow$ & $\downarrow$ & $\downarrow$ \\
\hline P4 & 140 & $\downarrow$ & $\downarrow$ & $\uparrow$ & & & $\downarrow$ & & & $\downarrow$ & $\uparrow$ & & $\downarrow$ & & $\uparrow$ & & $\downarrow$ & $\uparrow$ & $\downarrow$ \\
\hline
\end{tabular}

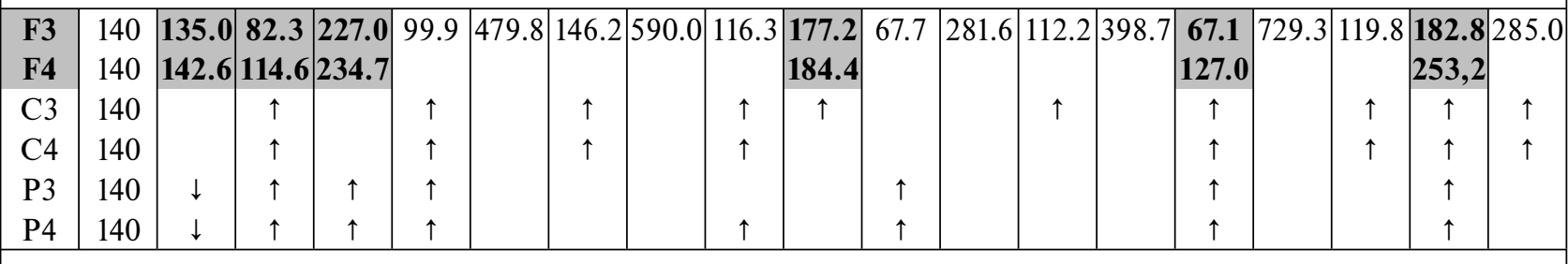

\begin{tabular}{|c|c|c|c|c|c|c|c|c|c|c|c|c|c|c|c|c|c|c|c|}
\hline F4 & 140 & 142.6 & 114.6 & 234.7 & 112.4 & 487.2 & 149.6 & 582.2 & 138.2 & 184.4 & 89.1 & 286.4 & 77.5 & 399.7 & 127.0 & 739.0 & 118.7 & 253.2 & 307.0 \\
C3 & 140 & $\downarrow$ & $\uparrow$ & & $\uparrow$ & & $\uparrow$ & & & & & & $\uparrow$ & & $\uparrow$ & & $\uparrow$ & $\uparrow$ & $\uparrow$ \\
C4 & 140 & $\downarrow$ & $\uparrow$ & & $\uparrow$ & & $\uparrow$ & & $\uparrow$ & & & & $\uparrow$ & & $\uparrow$ & & $\uparrow$ & $\uparrow$ & $\uparrow$ \\
P3 & 140 & $\downarrow$ & $\uparrow$ & & $\uparrow$ & & & & & $\downarrow$ & $\uparrow$ & & & & $\uparrow$ & & $\uparrow$ & $\uparrow$ & \\
P4 & 140 & $\downarrow$ & $\uparrow$ & & $\uparrow$ & & & & & $\downarrow$ & $\uparrow$ & & $\uparrow$ & & $\uparrow$ & & & $\uparrow$ & \\
\hline
\end{tabular}

\begin{tabular}{|c|c|c|c|c|c|c|c|c|c|c|c|c|c|c|c|c|c|c|c|c|}
\hline C3 & 140 & 135.3 & 181.0 & 228.6 & 189.3 & 481.5 & 232.0 & 581.9 & 185.2 & 190.6 & 96.8 & 280.5 & $\mathbf{1 6 4 . 7}$ & 395.9 & $\mathbf{1 7 8 . 3}$ & $\mathbf{7 3 7 . 1}$ & $\mathbf{1 9 5 . 6}$ & $\mathbf{4 3 4 . 6}$ & $\mathbf{4 5 3 . 5}$ \\
C4 & 140 & & & & & & & & & & & & $\mathbf{1 3 2 . 3}$ & & $\mathbf{2 5 2 , 0}$ & & & $\mathbf{4 9 0 . 0}$ & & \\
P3 & 140 & $\downarrow$ & & $\uparrow$ & & & $\downarrow$ & & & $\downarrow$ & $\uparrow$ & & $\downarrow$ & & $\uparrow$ & & $\downarrow$ & $\uparrow$ & $\downarrow$ & \\
P4 & 140 & $\downarrow$ & $\uparrow$ & $\uparrow$ & & & $\downarrow$ & & & & $\uparrow$ & & $\downarrow$ & & $\uparrow$ & & $\downarrow$ & $\uparrow$ & $\downarrow$ \\
\hline
\end{tabular}

\begin{tabular}{|c|c|c|c|c|c|c|c|c|c|c|c|c|c|c|c|c|c|c|c|} 
C4 & 140 & 134.0 & 183.8 & 231.7 & 197.4 & 476.0 & 216.1 & 582.7 & 188.6 & 181.3 & 108.2 & 283.8 & 132.3 & 396.0 & 252.0 & 732.3 & 195.6 & 490.0 & 455.6 \\
P3 & 140 & $\downarrow$ & & & $\uparrow$ & & $\downarrow$ & & $\downarrow$ & $\downarrow$ & $\uparrow$ & & & & & & & \\
P4 & 140 & $\downarrow$ & $\uparrow$ & & & & $\downarrow$ & & & & $\uparrow$ & & & & $\uparrow$ & & & $\uparrow$ & $\downarrow$ \\
\hline
\end{tabular}

\begin{tabular}{|l|l|l|l|l|l|l|l|l|l|l|l|l|l|l|l|l|l|l|l|l|}
\hline P3 & 140 & $\mathbf{1 2 0 . 5}$ & $\mathbf{2 1 1 . 2}$ & 234.0 & 235.0 & 488.6 & 154.0 & 580.8 & 153.5 & $\mathbf{1 7 1 . 3}$ & 261.2 & 283.2 & 102.4 & 399.9 & $\mathbf{2 6 3 . 6}$ & $\mathbf{7 3 3 . 6}$ & $\mathbf{1 5 3 . 8}$ & $\mathbf{5 2 3 . 2}$ & $\mathbf{3} 49.0$ \\
$\mathbf{P 4}$ & 140 & $\mathbf{1 2 3 . 3}$ & $\mathbf{2 8 4 . 5}$ & & & & & & & $\mathbf{1 7 6 . 6}$ & & & & & $\mathbf{3 4 9 . 8}$ & & & $\mathbf{6 4 6 . 3}$ & \\
\hline
\end{tabular}

The latencies or amplitudes are significantly higher $(\uparrow)$ or lower $(\downarrow)$ than the latencies or ampiltudes in a matching electrode. For the others see the text to Table 2.

The complete ERPs description also includes data on the timing of the responses - 980 ERPs were analysed. Mean latency of $\mathrm{P} 1$ ranged around $132 \mathrm{~ms}, \mathrm{P} 2$ around 229 ms, P3 around $483 \mathrm{~ms}, \mathrm{P} 4$ around $583 \mathrm{~ms}$, mean latency of $\mathrm{N} 1$ around $179 \mathrm{~ms}, \mathrm{~N} 2$ around $285 \mathrm{~ms}, \mathrm{~N} 3$ around $398 \mathrm{~ms}$ and N4 around $728 \mathrm{~ms}$.

\section{ERPs and their dependence on gender and site of recording electrodes}

Gender and location of the recording electrode significantly affect the latency and amplitude of select ERPs components to words (see the results of the multivariate analysis of variance in Table 1). No less significant is the interaction of the two independent variables, i.e. gender and site of the recording electrode.

Gender affects significantly only some of the measured ERPs features (see Table 2). Among them are latency of components LP2, LN1, LN2 and LN4, amplitude of positive components BP2, BP3 and BP4, amplitude of negative components $\mathrm{BN} 1, \mathrm{BN} 2$ and $\mathrm{BN} 4$, and also the values of the sum of amplitudes of the highest early positive peaks (P1/P2) and the third negativity - PV1, and values of the sum of the amplitude of the third, or perhaps the fourth positive peak, and the amplitude of the fourth negativity - PV2.

Location of the recording electrode on the scalp as well as gender influences the latency and amplitude of the analysed components of ERPs to word. This is evident from even superficial examination of data in Table 3, which sums up the main results of the comparison of each ERPs feature registered in seven different electrode sites on the scalp.

The amplitude of each ERPs component in site $\mathrm{Cz}$ in most cases is significantly higher than in the other tested sites. The only exception are electrodes $\mathrm{P} 3$ and $\mathrm{P} 4$, in which components BN1 and BN3 have a higher amplitude than the same ERPs components in site $\mathrm{Cz}$.

The table also illustrates the existence of significant differences in the mean latency and amplitude of some ERPs components registered in electrodes over the left 
Table 4. Comparison of individual festures of ERPs to words in the same site on the scalp in males (1) and females (2)

\begin{tabular}{|c|c|c|c|c|c|c|c|c|c|c|c|c|c|c|c|c|c|c|c|c|}
\hline \begin{tabular}{|c|} 
Gen- \\
der
\end{tabular} & \begin{tabular}{|l|} 
Elec- \\
trode
\end{tabular} & $\mathrm{N}$ & \begin{tabular}{|c|}
$\mathrm{L}$ \\
LP1 \\
\end{tabular} & $\begin{array}{c}\text { A } \\
\text { BP1 } \\
\end{array}$ & \begin{tabular}{|c|} 
L \\
LP2 \\
\end{tabular} & \begin{tabular}{|c|} 
A \\
BP2 \\
\end{tabular} & \begin{tabular}{|c|} 
L \\
LP3 \\
\end{tabular} & \begin{tabular}{|c|} 
A \\
BP3 \\
\end{tabular} & \begin{tabular}{|c|} 
L \\
LP4 \\
\end{tabular} & \begin{tabular}{|c|} 
A \\
BP4 \\
\end{tabular} & \begin{tabular}{|c|}
$\mathrm{L}$ \\
$\mathrm{LN} 1$ \\
\end{tabular} & \begin{tabular}{|c|} 
A \\
BN1 \\
\end{tabular} & \begin{tabular}{|c|}
$\mathrm{L}$ \\
$\mathrm{LN} 2$ \\
\end{tabular} & \begin{tabular}{|c|} 
A \\
BN2 \\
\end{tabular} & \begin{tabular}{|c|}
$\mathrm{L}$ \\
$\mathrm{LN} 3$ \\
\end{tabular} & $\begin{array}{c}\text { A } \\
\text { BN3 } \\
\end{array}$ & \begin{tabular}{|c|} 
L \\
LN4 \\
\end{tabular} & \begin{tabular}{|c|} 
A \\
BN4 \\
\end{tabular} & \begin{tabular}{|c|} 
A \\
PV1
\end{tabular} & \begin{tabular}{|c|} 
A \\
PV2 \\
\end{tabular} \\
\hline $\begin{array}{l}1 \\
2 \\
\end{array}$ & $\mathrm{Cz}$ & $\begin{array}{l}49 \\
91\end{array}$ & .8 & 227.0 & \begin{tabular}{|l|}
236.3 \\
219.7
\end{tabular} & $\begin{array}{r}123.4 \\
347.1 \\
\end{array}$ & 479.7 & 283.0 & 582.6 & \begin{tabular}{|l|}
237.1 \\
155.3
\end{tabular} & $\begin{array}{l}196.3 \\
176.9\end{array}$ & \begin{tabular}{|r|}
41.3 \\
49.5 \\
\end{tabular} & \begin{tabular}{|l|}
267.8 \\
288.8
\end{tabular} & $\begin{array}{l}155.0 \\
240.6 \\
\end{array}$ & 392.8 & 249.3 & $\begin{array}{l}752.4 \\
716.5 \\
\end{array}$ & 212.4 & \begin{tabular}{|l|}
472.8 \\
652.3
\end{tabular} & 20 \\
\hline $\begin{array}{l}1 \\
2 \\
\end{array}$ & $\mathrm{~F} 3$ & 91 & .2 & 0 & \begin{tabular}{|l|}
234.9 \\
219.0 \\
\end{tabular} & \begin{tabular}{|c|}
53.7 \\
146.2 \\
\end{tabular} & 476.6 & 152.6 & \begin{tabular}{|l|}
597.8 \\
\end{tabular} & |131.6 & \begin{tabular}{|l|}
182.2 \\
\end{tabular} & .0 & \begin{tabular}{|l|}
272.0 \\
291.3 \\
\end{tabular} & \begin{tabular}{|l|}
98.6 \\
\end{tabular} & 9.3 & 0.1 & \begin{tabular}{|l|}
745.4 \\
713.3 \\
\end{tabular} & 7.1 & \begin{tabular}{|l|}
126.5 \\
239.1 \\
\end{tabular} & \\
\hline $\begin{array}{l}1 \\
2\end{array}$ & & 91 & 4.7 & 110.7 & \begin{tabular}{|l|}
241.1 \\
228.3
\end{tabular} & 102.8 & 486.7 & 142.5 & 576.0 & \begin{tabular}{|l|}
146.9 \\
\end{tabular} & \begin{tabular}{|l|}
186.8 \\
\end{tabular} & \begin{tabular}{|l|}
106.6 \\
\end{tabular} & \begin{tabular}{|l|}
275.1 \\
297.7 \\
\end{tabular} & \begin{tabular}{|l|}
72.5 \\
\end{tabular} & 395.3 & \begin{tabular}{|c|}
98.2 \\
155.9 \\
\end{tabular} & \begin{tabular}{|l|}
759.0 \\
719.0 \\
\end{tabular} & 91.8 & \begin{tabular}{|l|}
203.0 \\
303.4
\end{tabular} & \begin{tabular}{|l|}
259 \\
354 \\
\end{tabular} \\
\hline $\begin{array}{l}1 \\
2 \\
\end{array}$ & & $\begin{array}{l}49 \\
91\end{array}$ & 4.0 & 176.2 & $\begin{array}{l}237.1 \\
220.2\end{array}$ & $\begin{array}{c}98.4 \\
280.0\end{array}$ & \begin{tabular}{|l|}
479.1 \\
\end{tabular} & 253.9 & \begin{tabular}{|l|}
578.7 \\
\end{tabular} & \begin{tabular}{|l|}
227.2 \\
143.1 \\
\end{tabular} & \begin{tabular}{|l|}
204.1 \\
177.1 \\
\end{tabular} & \begin{tabular}{|c|}
130.1 \\
63.5 \\
\end{tabular} & \begin{tabular}{|l|}
268.0 \\
293.1 \\
\end{tabular} & \begin{tabular}{|l|}
137.0 \\
192.3 \\
\end{tabular} & \begin{tabular}{|l|}
391.4 \\
\end{tabular} & \begin{tabular}{|l|}
161.8 \\
\end{tabular} & \begin{tabular}{|l|}
759.4 \\
714.9
\end{tabular} & \begin{tabular}{|l|}
172.0 \\
\end{tabular} & \begin{tabular}{|l|}
347.5 \\
521.6
\end{tabular} & 424 \\
\hline $\begin{array}{l}1 \\
2\end{array}$ & & $\begin{array}{l}49 \\
91\end{array}$ & 1.3 & 177.8 & \begin{tabular}{|l|}
240.0 \\
223.3
\end{tabular} & \begin{tabular}{|l|}
163.8 \\
230.9 \\
\end{tabular} & 468.3 & 219.7 & \begin{tabular}{|l|}
579.7 \\
\end{tabular} & \begin{tabular}{|l|}
220.8 \\
156.4
\end{tabular} & 183.1 & \begin{tabular}{|c|}
158.6 \\
57.7
\end{tabular} & \begin{tabular}{|l|}
274.0 \\
293.5
\end{tabular} & $\mid 108.1$ & 395.7 & 249.6 & \begin{tabular}{|l|}
752.4 \\
712.1 \\
\end{tabular} & \begin{tabular}{|l|}
170.0 \\
\end{tabular} & \begin{tabular}{|l|}
439.1 \\
540.9
\end{tabular} & 431 \\
\hline $\begin{array}{l}1 \\
2\end{array}$ & P3 & 91 & $\mid 122.3$ & 216.4 & 235.4 & \begin{tabular}{|l|}
185.1 \\
285.1 \\
\end{tabular} & \begin{tabular}{|l|}
490.1 \\
\end{tabular} & 182.8 & \begin{tabular}{|l|}
579.2 \\
\end{tabular} & \begin{tabular}{|l|}
205.9 \\
101.2
\end{tabular} & \begin{tabular}{|l|}
176.2 \\
\end{tabular} & 264.0 & 272.6 & $\mid$\begin{tabular}{|l|}
100.7 \\
\end{tabular} & \begin{tabular}{|l|}
399.1 \\
\end{tabular} & 276.7 & \begin{tabular}{|l|}
754.2 \\
713.0 \\
\end{tabular} & \begin{tabular}{|l|}
123.2 \\
184.4 \\
\end{tabular} & 518.3 & 352 \\
\hline 1 & 11 & קit & 2.9 & 283.3 & \begin{tabular}{|l|}
239.6 \\
228.5
\end{tabular} & $\begin{array}{l}199.6 \\
261.9\end{array}$ & 491.3 & 67.8 & \begin{tabular}{|l|}
580.1 \\
\end{tabular} & \begin{tabular}{|l|}
203.8 \\
125.4
\end{tabular} & 180.7 & \begin{tabular}{|l|}
295.0 \\
234.0
\end{tabular} & \begin{tabular}{|l|}
278.6 \\
290.5 \\
\end{tabular} & 116.4 & \begin{tabular}{|l|}
403.9 \\
\end{tabular} & 362.3 & \begin{tabular}{|l|}
748.8 \\
719.0
\end{tabular} & \begin{tabular}{|l|}
131.1 \\
\end{tabular} & 657.4 & 343 \\
\hline
\end{tabular}

For the other details see the text to Table 2.

hemisphere $(\mathrm{F} 3 / \mathrm{C} 3 / \mathrm{P} 3)$ and also in electrodes over the right hemisphere $(\mathrm{F} 4 / \mathrm{C} 4 / \mathrm{P} 4)$; as long as the differences are significant, then in the majority of cases the latencies are longer and the amplitudes higher in electrodes over the right hemisphere. In both hemispheres, however, the amplitude of each component is smallest in ERPs records in sites F3, F4 and largest in sites P3 and P4; the only exceptions are components $\mathrm{BP} 3, \mathrm{BP} 4$ and $\mathrm{BN} 3$, which reach their maximum in sites $\mathrm{C} 3$ and $\mathrm{C} 4$.

The mean latency and amplitude of some components (Table 3) distinguishes ERPs recorded simultaneously in symmetric sites on the right and left hemisphere (F3/F4, C3/C4, P3/P4). Amplitudes BP1, BN3 and PV1 are significantly higher in records from the right hemisphere. Latencies LP1 and LN1 in sites F4 and P4 behave in a similar way - they are longer; the latency differences of all components in sites $\mathrm{C} 3$ and $\mathrm{C} 4$ are statistically insignificant.

Moreover, a more detailed analysis of the data in Table 3 shows that the location of the recording electrode affects the amplitude of each component rather than their latencies; significant differences in latencies are restricted to the early ERPs waves, i.e. waves LP1, LP2 and LN1.

The results of the analysis of the interaction of gender and electrode location on the latency and amplitude of each ERPs component to word stimuli are summed up in Table 4. The data show interaction of both independent variables. Latencies of components LP2 and LN4 in all electrodes are shorter in females than in males, component LN2 behaves reversely - its latency is shorter in males. On the other hand, the amplitude of dependent variables BP2, BN2 and PV1 is in most electrodes higher in females than in males - except for the amplitude of components BP4 and BN1.

\section{DISCUSSION}

Language-related ERPs have been obtained with a variety of experimental paradigms by many researchers - see review $^{19-21}$. Here we are not going to specify their findings and confine ourselves to the statement that each of these reports has mentioned a negativity between 250 and $600 \mathrm{~ms}$, which appears to be sensitive to some linguistic or semantic variable. However, it is extremely difficult for the large variable distribution of ERPs negativities to compare them directly. Why is this so? What is the cause of the controversial findings?

A more detailed analysis of papers suggests that one of the causes of the different scores may consist in the experimental paradigm itself. For example, Kutas et al..$^{14,15}$ recorded ERPs as the subject silently read sentences, presented one word at a time, while others presented sentences or phrases and required the subject to decide about their validity ${ }^{5}$ or congruity ${ }^{17}$, farther examined the ERPs to word presented in isolation for subsequent naming ${ }^{24}$.

Quantitative and qualitative word properties also influence brain processes. From a number of paperse.g. 2, 18, 22 it follows that it is principally the length of the word, its frequency, concrete and abstract meaning, image ability, grammatical role of the word in the sentence, etc.

The results presented in this paper can partly contribute to uncovering the causes of unequal results. In our experiments visual verbal stimuli triggered ERPs formed by four positive and four negative waves. The high A/D conversion rate was a necessary condition for recording such ERPs; the low A/D conversion rate gave rise to ERPs with few waves, the latency and amplitude of which differed from that obtained at high $\mathrm{A} / \mathrm{D}$ conversion rate.

Analysis of results indicated that the amplitude of some waves of ERPs to verbal stimuli depends on two 
Appendix 1. Verbs and nouns used in the experiment

\begin{tabular}{|c|c|c|c|c|c|c|c|}
\hline & \multicolumn{3}{|c|}{ Verbs } & \multicolumn{4}{|c|}{ Nouns } \\
\hline & A & $\mathrm{C}$ & $\mathrm{F}$ & B & E & G & D \\
\hline 1 & Bědovat & Broukat & Brousit & Dobrota & Altán & Dláto & Beran \\
\hline 2 & Hladovět & Bublat & Hladit & Námaha & Bojler & Hoblík & Bizon \\
\hline 3 & Hloubat & Klesat & Hrabat & Návrh & Budova & Hřeben & Buvol \\
\hline 4 & Hodlat & Klokotat & Chytat & Obyčej & Hřiště & Kartáč & Gorila \\
\hline 5 & Chápat & Nasedat & Klepat & Ostuda & Jeřáb & Kleště & Hroch \\
\hline 6 & Litovat & Obíhat & Krájet & Ozvěna & Komín & Konev & Hříbě \\
\hline 7 & Namítat & Plachtit & Kousat & Pomluva & Kostel & Lopata & Hyena \\
\hline 8 & Naříkat & Plynout & Loupat & Postoj & Koryto & Lžíce & Kozel \\
\hline 9 & Pohrdat & Proudit & Malovat & Prokletí & Lešení & Nádoba & Kráva \\
\hline 10 & Prožívat & Pryštit & Natírat & Přednost & Lustr & Nůžky & Liška \\
\hline 11 & Studovat & Rotovat & Objímat & Příčina & Maják & Pilník & Mýval \\
\hline 12 & Toužit & Stékat & Sbirat & Přízeñ & Ohrada & Puška & Ovce \\
\hline 13 & Truchlit & Stoupat & Skládat & Radost & Orloj & Sekera & Panter \\
\hline 14 & Tříbit & Uhánět & Stříkat & Služba & Panel & Smeták & Pavián \\
\hline 15 & Usilovat & Vadnout & Svírat & Smutek & Sfinga & Stěrka & Prase \\
\hline 16 & Usuzovat & Vyrůstat & Škrabat & Surovost & Sloup & Svěrák & Srnka \\
\hline 17 & Uvažovat & Vzdouvat & Umývat & Úsudek & Socha & Štětec & Šakal \\
\hline 18 & Zastírat & Vzkvétat & Zametat & Užitek & Sporák & Tužka & Tchoř \\
\hline 19 & Závidět & Vznášet & Zápasit & Výmysl & Strom & Utěrka & Vydra \\
\hline 20 & Žasnout & Zapadat & Zvedat & Záliba & Studna & Volant & Zebra \\
\hline 21 & Žíznit & Zurčet & Žehlit & Žaloba & Závora & Žínka & Žirafa \\
\hline
\end{tabular}

Subclasses of verbs: A - abstract, C - motion, F - action.

Subclasses of nouns: B - abstract, E - visual, G - motor, D - animal names.

independent variables - gender and the site of recording electrode. Both independent variables strongly affect the amplitude of some ERPs waves.

It was also found that the amplitude of each wave of ERPs has a high degree of inter-individual variability - low or high amplitude of some ERPs waves strongly modifies its definitive shape.

To sum up briefly: In an analysis and comparison of parameters of various ERPs to the same or different language-related stimuli, it is necessary to take into consideration the inter-individual variability of the ERP waves, their dependence on gender and the site of the recording electrode, the rate of A/D conversion, word properties and experimental paradigm.

\section{ACKNOWLEDGEMENTS}

The author wishes to thank Mrs. S. Řeznícková for her valuable technical assistance and for advice in statistical processing of data to Ing. L. Čižek.

\section{REFERENCES}

1. Bradley DC, Garrett MF. (1983) Hemispheric differences in the recognition closed- and open- class words. Neuropsychologia 21, 155-159.

2. Brown CM, Hagoort P, Keurs M. (1999) Electrophysiological sig- natures of visual lexical processing: open- and closed-class words. J Cogn Neurosci 11, 261-281.

3. Caramazza A, Zurif EB. (1976) Dissociation of algorithmic and heuristic processes in language comprehension: evidence from aphasia. Brain Lang 3, 572-582.

4. Caramazza A, Hillis AE. (1991) Lexical organization of nouns and verbs in the brain. Nature $349,788-790$.

5. Fischler I, Bloom PA, Childers DG, Roucos SE, Perry NW. (1983) Brain potentials related to stages of sentence verification. Psychophysiology 20, 400-409.

6. Friederici AD. (1983) Aphasics' perception of words in sentential context: Some real-time processing evidence. Neuropsychologia 21, 351-358.

7. Friederici AD. (1985) Levels of processing and vocabulary types: evidence from on-line comprehension in normals and agrammatics. Cognition 19, 133-166.

8. Fromkin VA. (1995) Introduction to special issue: Linguistic representational and processing analysis of agrammatism. Brain Lang 50, $1-9$.

9. Chiarello C, Nuding S. (1987) Visual field effects for processing content and function words. Neuropsychologia 25, 539-548.

10. Jasper HH. (1958) The ten twenty electrode system of the international federation. Electroencephalog Clin Neurophysiol 10, 371-375.

11. Jelínek J, Bečka VJ, Těšitelová M. Frekvence slov, slovních druhů a tvarů v českém jazyce. Praha: SPN, 1961.

12. Johnson Jr R. (1993) On the neural generators of the P300 component of the event-related potential. Psychophysiology 30, 90-97.

13. Kellenbach ML, Wijers AA, Hovius M, Mulder J, Mulder G. (2002) Neural differentiation of lexico-semantic categories or semantic features? Event-related potential evidence for both. J Cogn Neurosci 14, 561-577.

14. Kutas M, Hillyard SA. (1980) Reading senseless sentences: brain potentials reflect semantic incongruity. Science 207, 203-205. 
15. Kutas M, Hillyard SA. (1984) Brain potentials during reading reflect word expectancy and semantic association. Nature 307, $161-163$.

16. Mohr B, Pulvermüller F, Zaidel E. (1994) Lexical decision after left, right and bilateral presentation of words, function words and non-words: Evidence for interhemispheric interaction. Neuropsychologia 32, 105-124.

17. Neville HJ, Kutas M, Chesney G., Schmidt A. (1986) Event-related brain potentials during initial encoding and subsequent recognition memory of congruous and incongruous words. J Mem Lang 25, 75-92.

18. Osterhout L, Bersick M, McKinnon R. (1997) Brain potentials elicited by words: word length and frequency predict the latency of an early negativity. Biol Psychol 46, 143-168.
19. Petřek J. (2004) Aktivita mozku při zpracování jazyka. Čs. Fyziol 53, 125-131.

20. Pulvermüller F. (1999) Words in the brain's language. Behav Brain Sci 22, 253-336.

21. Pulvermüller F. (2002) A brain perspective on language mechanisms: from discrete neuronal ensembles to serial order. Prog Neurobiol 67, 85-111.

22. Pulvermüller F, Lutzenberger W, Birbaumer N. (1995) Electrocortical distinction of vocabulary types. Electroencephalog Clin Neurophysiol 94, 357-370.

23. Roth Z, Josífko M, Malý V, Trčka V. Statistické metody v experimentální medicíně. Praha: SZdN, 1962.

24. Stuss DT, Sarazin FF, Leech EE, Picton TW. (1983) Event related potentials during naming and mental rotation. Electroencephalog Clin Neurophysiol 56, 133-146. 